\title{
TIPOS DE VEGETAÇĀO METALÓFILA EM ÁREAS DA SERRA DE CARAJÁS E DE MINAS GERAIS, BRASIL
}

\author{
Maria Luiza Porto ${ }^{1}$ \\ Manoela F. F. da Silva ${ }^{2}$
}

Recebido em 10-3-89. Aceito em 2-2-90

RESUMO - Em áreas da Serra de Carajás, Pará, e em áreas da Cadeia do Espinhaço, Minas Gerais, Brasil, foram coletadas plantas e nelas analisadas as concentrações de $\mathrm{Cu}, \mathrm{Pb}, \mathrm{Ni}, \mathrm{Cd}, \mathrm{Cr}, \mathrm{Co}, \mathrm{Mn}$ e $\mathrm{Fe}$. Os resultados indicam que as plantas das áreas de Carajás concentram $\mathrm{Cu}, \mathrm{Pb}, \mathrm{Ni}, \mathrm{Cr}$ e $\mathrm{Fe}$ acima da normalidade e que as plantas das áreas da Cadeia do Espinhaço concentram $\mathrm{Ni}, \mathrm{Mn}, \mathrm{Cu}, \mathrm{Pb}, \mathrm{Cd}$ e também $\mathrm{Fe}$. Com base nestes resultados e nos aspectos fisionômicos da vegetação, podemos supor a existência de diferentes tipos de vegetação metalófila nestas áreas, as quais podem pertencer a uma única provír. ia biogeoquímica (Carajás - Espinhaço), rica em ferro e outros metais pesados.

Palavras-chave: vegetação, solos metalíferos, metais pesados em plantas.

\begin{abstract}
Plants from Serra dos Carajás, state of Pará, and Cadeia do Espinhaço, state of Minas Gerais, Brazil, were analyzed for $\mathrm{Cu}, \mathrm{Pb}, \mathrm{Ni}, \mathrm{Cd}, \mathrm{Co}, \mathrm{Mn}$ and $\mathrm{Fe}$ concentrations. The results indicate that plants from Carajás concentrate $\mathrm{Cu}, \mathrm{Pb}$, $\mathrm{Ni}, \mathrm{Cr}$ and $\mathrm{Fe}$ above background values, and those from the state of Minas Gerais concentrate $\mathrm{Ni}, \mathrm{Mn}, \mathrm{Cu}, \mathrm{Pb}, \mathrm{Cd}$ and also $\mathrm{Fe}$. Based on the results and on the physionomical aspects of the vegetation we can $\mathrm{S}$; :culate on the existence of differente types of metalophylic vegetation in these areas, which may belong to a single biogeochemical province (Carajás - Espinhaço) which is rich in iron and other heavy metals.
\end{abstract}

Keywords: vegetation, metalliferous soils, heavy metals in plants.

1 - Departamento de Botánica e Centro de Ecologia da Universidade Federal do Rio Grande do Sul. Avenida Paulo Gama s/n, 90049, Porto Alegre, RS, Brasil.

2 - Museu Paraense Emflio Geoldi, Avenida Perimetral s/n, Bairro Terra Firme, Caixa Postal 399, 66000 , Belém, PA, Brasil. 


\section{Introdução}

O estudo das plantas indicadoras de metais no solo teve ińcio, de uma maneira mais sistemática, com os trabalhos de Linstow (1929) e Victorov (1947), sendo o primeiro, o criador da denominação 'Bodenanzeiger' dada às plantas indicadoras de metais no solo. Ernst (1974) editou o livro "Schwermetallvegegation der Erde" ' IVegetaçâo metalofila (de metais pesados) da Terra], onde fica consagrado o termo "Schwermetallvegetation". Nesta obra também é citada a inexistência de trabalhos sobre este tipo de vegetação para a América do sul, apesar de saber-se da grande riqueza mineral af existente. Somente em Porto (1981) é que este tipo de vegetação foi citado para o Brasil, em uma região rica em minério de cobre, chumbo, prata e ouro, situada no escudo cristalino do Rio Grande do Sul.

A vegetação metalófila se caracteriza por espécies vegetais que, muitas vezes, apresentam nanismo ou gigantismo e, ao mesmo tempo, altas concentrações de metais em seus tecidos. Por outro lado, verificam-se mecanismos de tolerância às condições extremas dos solos metalíferos, através de alterações fisiológicas, especialmente metabólicas, e modificações da morfologia interna e externa das plantas, levando à seleção de indivíduos nestes ambientes. Freqüentemente, af são encontrados endemismos e novas espécies.

Os aspectos fisionômicos contrastantes da vegetação existente em áreas da Cadeia do Espinhaço (Minas Gerais) e da Serra dos Carajás (Pará), assim como a ocorrência conhecida de minerais metálicos nestes solos, nos levaram a supor a existência de uma vegetação adaptada a estas condições. Vegetação esta que teria a capacidade de concentrar fons de metais pesados, os quais foram abordados no presente trabalho, procurando dar uma explicação à complexidade do mosaico vegetacional existente nestas regiões.

\section{Material e Métodos}

Sabendo-se do potencial mineralógico das áreas da Cadeia do Espinhaço (Três Moinhos, Lavras Novas e Serra do Caraça), assim como daquelas existentes na Serra dos Carajás, coletaram-se plantas, ao acaso, em diferentes formações vegetais destas áreas. Folhas e inflorescências foram secas em papel não impresso e, posteriormente, utilizaram-se $100 \mathrm{mg}$ destas para digestão em $2 \mathrm{ml}$ de $\mathrm{HNO}^{3}$ concentrado (65\%). A digestão foi feita com auxflio de bombas de pressão, com recipiente interno de teflon.

A determinação da concentração dos fons metálicos nos tecidos foi feita com o auxflio de um espectrofotômetro de absorção atômica (Perkin-Helmer 2380), acoplado com forno de grafite (Perkin-Helmer-HGA 400). Os valores de concentração dos fons metálicos obtidos são dados em partes por milhão (ppm), em relação ao peso seco. 
Tipos de vegetação metalófila em áreas da ...

\section{Resultados}

\section{1 - Descrição das áreas}

Na Serra dos Carajás, especialmente nas áreas próximas à exploração de ferro, onde as altitudes estão em torno de $200-700 \mathrm{~m}$, verifica-se a existência de um mosaico de vegetação formado por uma floresta higrofila intercalada por formações dos tipos savana, savana arbustiva e estepe. Estes três últimos tipos encontram-se, predominantemente, sobre a denominada canga. As especies mais freqüentes nestes locais são Callisthene cf. minor Mart. e Mimosa acutistipula var. nigra Huber.

A fisionomia desta vegetação varia em função da estação climática. Durante os tempos chuvosos (novembro a abril), a vegetação cobre-se de um verde intenso e muitas espécies florescem, destacando-se Ipomoea cavalcantei D. Austin, Aspilia vanderbergiana J. U. Santos, Vernonia muricata DC, Begonia goianensis DC, Begonia humilis Ait., Mimosa sominians H.B.K. e a orquídea Sobralia liliastrum Lindl. No estrato herbáceo, destacam-se Trachypogon macroglossus Trin. e Axonopus cf. leptostachyus (Flueg.) Hitch. Em alguns trechos, as ervas tornam-se rarefeitas, ficando as rochas ferríferas desnudas de vegetação, desenvolvendo-se, neste caso, um reduzido número de espécies entre as fendas.

As áreas observadas em Minas Ge is foram três. Uma situa-se próximo à localidade de Três Moinhos, no municipio de Ouro Preto, que corresponde às regiões menos elevadas junto à Cadeia do Espinhaço. Nesta área, a vegetação dos vales e vertentes tende a mista e do tipo floresta subtropical, com ocorrência de Drimys brasiliensis Thell e Podocarpus sellowii Kl. Circundando estas áreas, nas regiôes um pouco mais elevadas, temos elementos típicos de cerrado.

Outra área observada foi na região da Serra do Caraça, onde se verificam formações de granito e de sedimentos antigos, instalando-se uma vegetaçãc do tipo savana com dominância de Vanillosmopsis erythropappa Sch. Bip. Nas fendas das rochas, ê freqüente encontrar-se uma espécie do gênero Cambessedesia.

Já sobre as maiores elevações da Cadeia do Espi haço, observa-se, em direção à localidade de Lavras Novas, uma vegetação campestre, com arbustos isolados. Nesta área, o substrato é rico em quartzito, encontrando-se um número elevado de fragmentos de cristais de quartzo misturados com solo escuro do tipo turfoso. Neste caso, a rocha-mãe provavelmente é do tipo ácido intrusivo. No estrato herbáceo, predominam gramíneas, destacando-se as espécies do gênero Panicum. Ervas mais robustas são af encontradas, como Eriocauláceas, Veloziáceas e Xiridáceas, alêm de Labiadas, Compostas e Melastomatáceas.

\section{2 - Concentração de Metais}

A tabela 1 apresenta os conteudos foliares de cobre, chumbo, cromo, ni- 
quel, manganês e ferro em plantas da Serra dos Carajás. Neste caso, verifica-se concentração acima da normalidade em plantas, para cobre em sete especies, para chumbo em cinco espécies, para níquel em três espécies, para ferro em três espécies e para cromo em todas as espécies, sendo a erva Cuphea tenella a que melhor concentrou os fons metálicos, apresentando, porém, exceção para ferro e manganês. É interessante destacar a existência de algumas plantas que concentram especificamente, como Mimosa sominians para níquel e talvez cromo e ferro, assim como Dioclea crenata para o cobre e talvez ferro e cromo.

Na região de Três Moinhos (Minas Gerais), foram anulisadas três espécies quanto ao conteúdo de cobre, cádmio, chumbo, molibdênio, níquel, manganês e ferro, sendo interessante ressaltar anomalias para manganês, ferro e cádmio em Podocarpus sellowii e de níquel em Erytroxylum sp. Isto leva a pensar que, nestas áreas, as rochas são básicas (tabela 2).

$\mathrm{Na}$ Serra do Caraça, Vanillosmopsis demonstrou concentrar cobre, níquel e cádmio, e Cambessedesia, chumbo. Por estas concentrações de metais nas plantas é de se supor que, nesta área, ocorram os minerais sob forma de sulfetos como normalmente se verifica para ocorrências de cobre de chumbo (tabela 2).

Quanto à concentração de metais nas folhas, destaca-se uma espécie de Paepalanthus, que apresenta valores acima da normalidade para chumbo e ferro e, na inflorescência, extraordinária concentração de cobre, chumbo e níquel. Outra espécie que demonstrou concentração acima da normalidade foi Hyptis sp, para chumbo e níquel (tabela 2).

Pelo valor de concentração dos fons nestas plantas é de se supor que, nestes locais, encontra-se uma quantidade relativamente alta destes elementos no solo e, pela presença dos seixos de quartzo, é de se supor, ainda, a associação de vários outros elementos do grupo dos metais raros, como tório, urânio, wolfrâmio e outros, encontrados normalmente sob forma de óxidos.

\section{Discussão}

Pela concentração dos fons metálicos nos tecidos das plantas examinadas, podemos levantar a hipotese de que, nas áreas consideradas, ocorre o que podemos denominar de vegetação metalofila em todas as suas expressões, desde o tipo floresta baixa, passando por savana arbustiva ate formações tipicamente campestres, como as estepes. As denominações fitogeográficas dadas a estas formações têm sido, ate então, objeto de discussão dos botânicos brasileiros. Para alguns, trata-se de 'campos rupestres' o que se encontra em Carajás e sobre a Cadeia do Espinhaço (Silveira, 1908; Joly, 1970); para outros, trata-se de uma 'vegetação de canga', especialmente aquela que ocorre em Carajás (Silva et al., 1986). Saint Hilaire (apud Romariz, 1986), em suas viagens na Província de Minas Gerais, refere-se também a estas áreas, denominando-as de 'carrascos' e 'carrasqueiros', destacando a importância do solo na modificação fisionômica da vegetação. Por outro lado, os tipos florestas e savanas metalofilas 
identificam-se com denominações em bases geoquímicas para os tipos de vegetação serpentina e galmai, respectivamente (Books, 1972, 1983). Este mesmo autor cita a existência de outros tipos de vegetação metalófila encontrados em regiões da África, as quais não denomina, e que possivelmente correspondem ao tipo estepe das áreas aqui consideradas.

Esta nomenclatura acima discutida, na realidade refere-se somente a aspectos fisionômicos ou geoquímicos, não levando em consideração a problemática biogeoquímica, que é discutida e proposta por Kovalskij (1977), a qual trata dos organismos e suas trocas com elementos presentes no solo ou com poluentes da biosfera. É a ciência do efeito das trocas ao nível dos organismos, da população, das biocenoses, das províncias biogeoquímicas, assim como das sub-regiões e regiões da biosfera. No caso das províncias biogeoquímicas, como é de se supor que seja Carajás - Espinhaço, a pressão do meio exercida pelos metais pesados é tamanha que leva ao desenvolvimento de um reduzido número de espécies nestas áreas. Esta seletividade se dá pela capacidade de tolerância que os organismos têm a estas condições extremas, podendo estes apresentarem mecanismos fisiológicos adaptativos e, ao mesmo tempo, modificarem sua forma de vida e sua morfologia interna e externa.

Caso a presença dos metais pesados no solo seja o principal fator de pressão sobre os organismos, caberia propor-se para as áreas estudadas, a denominação de florestas, savanas, savanas arbustivas e estepes metalófilas da província biogeoquímica Carajás - Espinhaço. Esta denominação pode encontrar apoio nas propostas de Ab'Saber $(1967,1977)$ sobre a faixa transicional entre os domínios morfoclimáticos, sendo que, segundo Vanzolini \& Brandão (1986), esta faixa não constitui forçosamente uma transição gradual entre dois domínios, mas, em geral, apresenta extrema setorialização, isto $E$, uma grande variedade de faces locais, como se constatou para os arredores de Ouro Preto e Mariana; estes amplos corredores entre os domínios morfoclimáticos, como afirmam autores, são as áreas ecologicamente mais heterogêneas do Brasil tropical.

$\mathrm{Na}$ realidade, elementos morfoclimáticos contrastantes, presentes em uma área montanhosa, situada em região ecologicamente diversificada, podem agir sobre a seleção dos organismos. Porém, os fatores que agem, possivelmente de maneira mais direta, como as trocas entre o solo e os organismos, talvez tenham maior expressão sobre estes, podendo levar à seleção e, conseqüentemente, a endemismos, como se verifica em outros tipos de vegetação metalófila do mundo.

Estudos posteriores integrados deverão ser executados para que se possa fazer uma real avaliação da problemática entre as trocas dos organismo com o solo, podendo, assim verificar-se a real influência sobre a composição e fisionomia da vegetação e sobre a sua fauna associada. 


\section{Conclusões}

A análise das plantas em áreas de solos metalfferos de Minas Gerais (Espinhaço) e do Pará (Serra dos Carajás) levou à constatação da concentração de diferentes íons metálicos nestas plantas. Estas concentraçōes, associadas à modificação fisionômica da vegetação, sugerem a ocorrência do que podemos denominar vegetação metalofila. Pode-se, ainda, supor que as áreas aqui estudadas pertençam a uma única província biogeoquímica com vriações locais, Carajás - Espinhaço, que se caracteriza pela riqueza de ferro e outros metais pesados no solo, exercendo estes uma pressão seletiva sobre os organismos tanto vegetais como animais.

\section{Referências Bibliográficas}

AB'SABER, A.N. 1967. Dominios morfoclimáticos e provincias fitogeográficas do Brasil. Departamento de Geografia da Universidade de São Paulo, 3: 45-48.

. 1977. Os domínios morfoclimáticos da América do Sul; primeira aproximação. Geomorfologia 52. 21p. map.

ALLEN, S., GRIMSHAW, M. H., PARKINSON, J.A. \& QUARBY, C. 1974. Chemical Analyses of Ecological Materiais. Oxford. Blanckwel.

BROOKS, R.R. 1972. Geobotany and Biochemistry in Mineral Exploration. Harper and Row. New York.

1983. Biological Methods of Prospecting for Minerals. John Wiley \& Sons, New York.

ERNST, W. 1974. Schwermetallvegetation der Erde. Gustav Fischer. Stuttgart. JOLY, A.B. 1970. Conheça a Vegetação Brasileira. EDUSP. São Paulo.

KOVALSKIJ, V.V.M. 1977. Geochemische Okologie. Dtsch. Landwirtschaft. Berlin Or.

LINSTOW, von O. 1929. Bodenanzeiger Pflanzen. Abh. Preuss. Geol. Land., 114: 1-105.

PORTO, M.L. 1984. Beiträge zur Schwermetallvegetation von Rio Grande do Sul, Brasilien. Tese de Doutoramento. Univ. de Ulm, Rep. Fed. da Alemanha.

SILVA, M.F.F., MENEZES, N.L., CAVAlCANTE, P.B. \& JOLY, C.A. 1986. Estudos botânicos: histórico, atualidade e perspectivas. In: Carajás - Desafio Poltitico, Ecologia e Desenvolvimento. CNPq, Ed. Brasiliense. Brasília.

SILVEIRA, A.A. 1908. Flora e Serras Mineiras. Empre. Off. Belo Horizonte. ROMARIZ, d. 1986. Viagens de Saint-Hillaire a Minas Gerais (sua contribuição para o estudo da vegetação). Conferência. XXXVII Congresso Nacional de Botânica, Ouro Preto, MG. São Paulo. mimeo. 
Tipos de vegetação metalófila em áreas da ...

VANZOLINI, P. \& BRANDÃO, C.R.F. 1986. Diretrizes gerais para um levantamento faunístico. In: Carajás - Desafio Politico, Ecologia e Desenvolvimento. CNPq, Ed. Brasiliense. Brasília.

VICTOROV, S.V. 1947. Biological Indicators in Geology. USP. Sovrem. Biol., 23 (2). 
TABELA 1

Espécies da Savana Metalofila de Carajás

Valores em ppm

\begin{tabular}{|c|c|c|c|c|c|c|}
\hline & $\mathrm{Cu}$ & $\mathrm{Pb}$ & $\mathrm{Cr}$ & $\mathrm{Ni}$ & $\mathrm{Nm}$ & $\mathrm{Fe}$ \\
\hline Axonopus cf. leptostachyus (Flueg.) Hitchoc & 16,00 & 1,43 & 0,87 & 2,30 & 18,03 & 334,53 \\
\hline Cuphea anulata Kaehne. & $141,67^{*}$ & $44,05^{*}$ & $1,93^{*}$ & $5,95^{*}$ & 151,65 & 369,15 \\
\hline Cuphea tenella Hook et Arn. & $158,14^{*}$ & $58,61^{*}$ & $1,61^{*}$ & $5,38^{*}$ & 107,10 & 373,34 \\
\hline Bauhinia pulchella Benth. & $102,14^{*}$ & $40,01^{*}$ & $1,48^{*}$ & 3,61 & 173,60 & 305,29 \\
\hline Byrsonima coriacea DC. & $133,61^{*}$ & $46,96^{*}$ & $1,12^{*}$ & 4,25 & 7,98 & 255,59 \\
\hline Dioclea crenata & $26,08^{*}$ & 2,93 & $17,27^{*}$ & 4,54 & 101,89 & $3.561,08^{*}$ \\
\hline Eugenia punicaefolia DC. & 21,43 & 1,43 & 0,41 & 2,90 & 154,97 & 349,98 \\
\hline Mimosa sominians Huher et Bonpl. & 17,59 & 1,60 & $9,06 *$ & $5,56^{*}$ & 123,57 & $1.857,50^{*}$ \\
\hline Norantea goyasensis Cambess. & $114,87^{*}$ & $38,42^{*}$ & $1,27^{*}$ & 3,08 & 57,94 & 255,72 \\
\hline Trachipogon macroglossus Trin. & 11,49 & 1,93 & $15,27^{*}$ & 3,85 & 113,93 & $1.899,86^{*}$ \\
\hline $\begin{array}{l}\text { Normalidade segundo Allen et al. }(1974) \\
\mathrm{Cu}=2,5-22 \mathrm{ppm} \quad \mathrm{Ni}=0,5-5 \mathrm{ppm} \\
\mathrm{Pb}=0,05-3 \mathrm{ppm} \quad \mathrm{Cr}=0,05-0,5 \mathrm{ppm} \\
\text { *- Indica valores acima da normalidade = anar }\end{array}$ & \multicolumn{3}{|c|}{$\begin{array}{l}\mathrm{Mn}=50-1000 \mathrm{ppm} \\
\mathrm{Fe}=40-500 \mathrm{ppm} \\
\text { lias botânicas. }\end{array}$} & \multicolumn{3}{|c|}{$\begin{array}{l}\mathrm{Cd}=0,01-0,3 \mathrm{ppm} \\
\mathrm{Mo}-0,1-0,8 \mathrm{ppm}\end{array}$} \\
\hline
\end{tabular}


₹

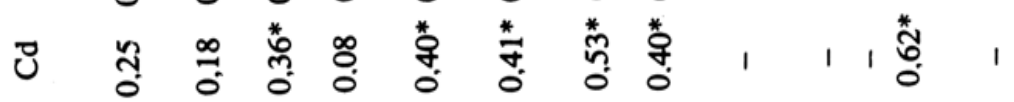

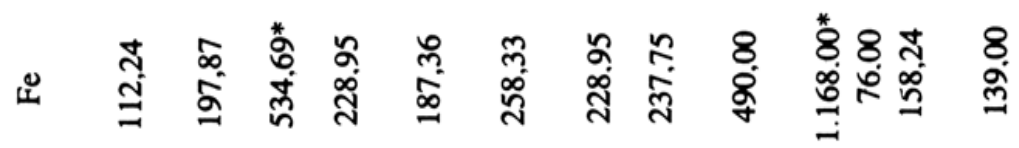

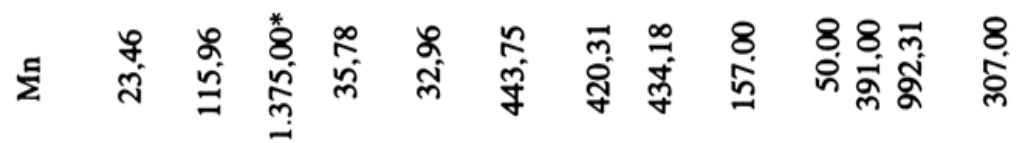

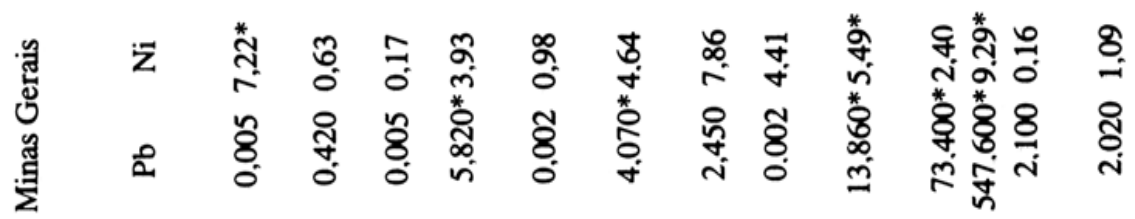

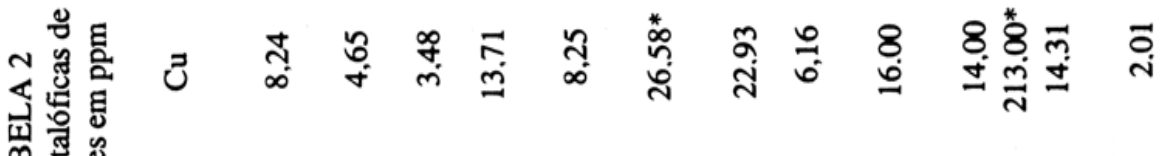

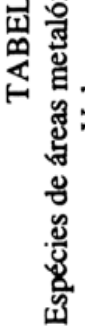

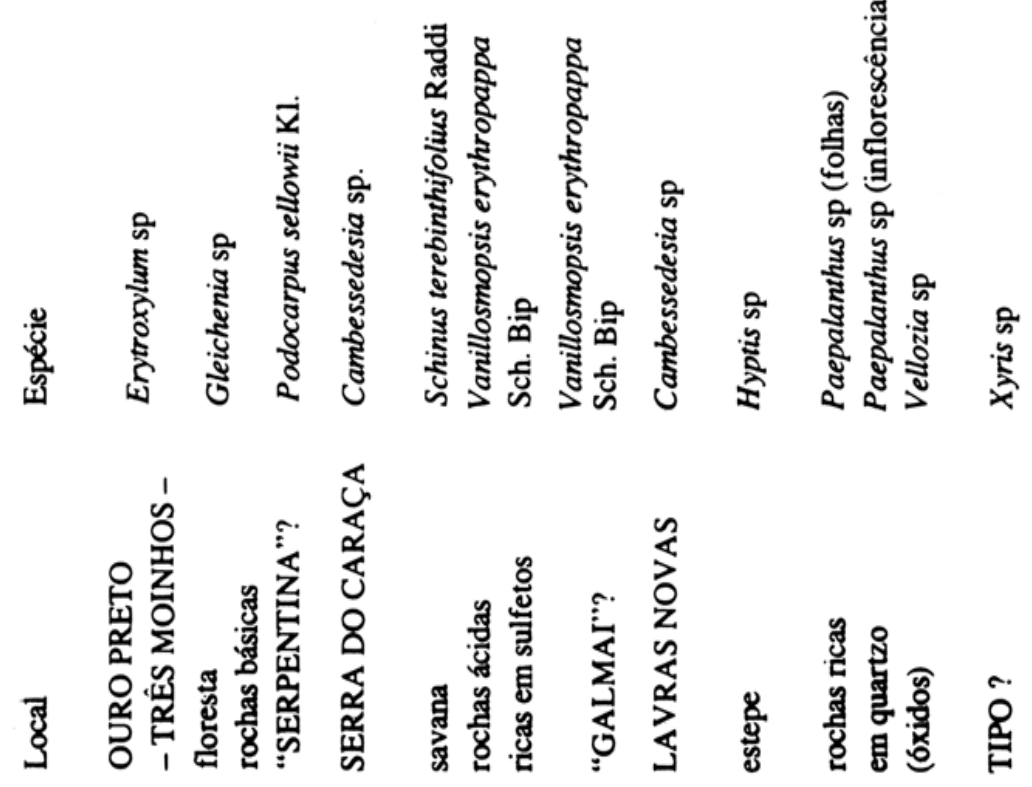

